\title{
Doze anos de estudo da Revista de Administração Pública à luz da bibliometria e da rede social
}

\section{Twelve years of study Journal Public Administration in the light of the bibliometry and of the social network}

\author{
Henrique César Melo Ribeiro'1
}

\section{Resumo}

Este artigo explorou a produção acadêmica científica da Revista de Administração Pública (RAP) no período de 2000 a 2011. O estudo baseou-se num estudo bibliométrico e de rede social utilizando-se da estatística descritiva em 669 artigos identificados. Os principais resultados foram: predominância de autoria em parceria; observou-se que a FGV (RJ) é a IES mais importante e influente no contexto da RAP, no que tange à proficuidade nos artigos publicados e na centralidade de grau; constatou-se a alta centralidade de rede dos coautores, influenciando em laços fracos entre esses atores do periódico ora investigado; a abordagem qualitativa se destacou nos 669 artigos investigados; e as palavras "gestão" e "pública" realçaramse nos títulos e nas palavras-chave. Conclui-se que o acervo dos 669 artigos investigados da Revista de Administração Pública reflete o universo da produção acadêmica da área de administração pública, ajudando, assim, a ampliar, difundir e socializar a área por meio de artigos acadêmicos publicados.

Palavras-chave: Revista de Administração Pública. Ensino e Pesquisa em Administração. Bibliometria. Rede Social.

\section{Abstract}

This article explored the academic scientific Journal Public Administration (JPA) in the period 2000-2011. The study was based on a bibliometric study and social networking, using descriptive statistics, in 669 articles identified. The main results of

Doutor em Administração pela Universidade Nove de Julho (Uninove-SP); Mestre em Administração pela Universidade de Fortaleza (Unifor-CE). Especialista em Controladoria Governamental e Docência do Ensino Superior pela Faculdade Piauiense (FAP-PI). Graduado em Ciências Contábeis pela Universidade Federal do Piauí (UFPI). Professor do Mestrado Profissional em Administração/Gestão do Esporte (Uninove-SP). Endereço: Rua Guará, n. 23, Bairro: São Judas Tadeu, Parnaíba-PI. E-mail: hcmribeiro@gmail.com. (86) 9543-8000. 
this study were predominantly written in partnership, the FGV (RJ) is the IES most important and influential in the context of RAP, with respect to articles published on the usefulness and degree centrality; it was also high network centrality of the co-authors, and acting on weak ties between these actors now investigated the journal; the qualitative approach stood in 669 articles investigated; and the words "management" and "public" is highlighted in the titles and keywords. It follows that the collection of 669 articles investigated the Journal of Public Administration, reflecting the world of academic research in the area of public administration, helping to expand, disseminate and socialize the area through academic papers published.

Keywords: Journal of Public Administration. Education and Research in Administration. Bibliometrics. Social Network.

\section{Introdução}

O desenvolvimento, disseminação e utilização do conhecimento científico em qualquer área acadêmica dependem de maneira relativa da circulação de ideias por meio dos estudos acadêmicos que aparecem nos livros didáticos e principalmente nas revistas científicas (HOFFMAN; HOLBROOK, 1993). Tal ação é vital para que haja uma renovação do pensamento científico na área de administração no Brasil, impactando na prática organizacional, na gestão e nas políticas públicas (CAMPOS; COSTA, 2007).

Verifica-se um crescimento, nos últimos anos, da produção acadêmica em administração no Brasil, influenciando a divulgação sistêmica em periódicos de excelência e abrangência nacional (JABBOUR; SANTOS; BARBIERI, 2008).

Nesse panorama, evidencia-se a Revista de Administração Pública (RAP), criada em 1967, sendo considerado um dos mais importantes e influentes periódicos da área de administração (RAP, 2012). Segundo Motta (2007), a RAP, em seus primeiros 20 anos, teve impacto direto no crescimento da administração pública no Brasil. A revista tem como missão:

Estabelecer e acompanhar a agenda das principais temáticas contemporâneas e prospectivas da gestão, 
promovendo o encontro entre o universo conceitual em evolução e as demandas da prática gerencial cotidiana de administradores orientados para mudanças. (RAP, 2012)

Este artigo, portanto, trará uma maior reflexão sobre o ensino em administração, especificamente na administração pública, ampliando seu foco no Brasil (OLIVEIRA; SAUERBRONN, 2007).

ARAP é o periódico mais indicado para tal, pois produz e dissemina conhecimento sobre a arte de governo/gestão pública no Brasil, sendo considerado um canal amplo de divulgação dessa produção científica, bem como da produção nacional em geral (MARTINS, 2007).

Ressalta-se que a bibliometria é uma técnica de pesquisa que analisa publicações em livros, relatórios e periódicos acadêmicos científicos (FERREIRA, 2011). Esta pesquisa focou-se na observação e nas análises bibliométricas (RAMOS-RODRÍGUEZ; RUÍZ-NAVARRO, 2004), bem como na análise de redes sociais, para avaliar a estrutura de relacionamento entre os autores (NERUR; RASHEED; NATARAJAN, 2008) e as Instituições de Ensino Superior (IES) (FRANCISCO, 2011; GONZALO et al., 2009) nos 669 artigos investigados na RAP.

A revisão da literatura permite-nos identificar diversos trabalhos bibliométricos e de rede social já realizados, especificamente sobre revistas, como os de Hoffman e Holbrook (1993), Ramos-Rodríguez e Ruíz-Navarro (2004), McMillan e Casey (2007), Robertson (2008), Ullah, Butt e Haroon (2008), Fernandez-Alles e Ramos-Rodríguez (2009), Durisin, Calabretta e Parmeggiani (2010), Borba, Hoeltgebaum e Silveira (2011), Ferreira et al. (2011), Francisco (2011), Mascarenhas, Zambaldi e Moraes (2011) e Bortollossi e Sampaio (2012).

Diante disso, evidencia-se a questão de pesquisa que norteou este trabalho: qual é o perfil da produção acadêmica científica da RAP no período de 2000 a 2011 ?

Este artigo está organizado em cinco partes. A primeira evidencia a introdução, com a justificativa, questão e o objetivo do trabalho. 0 
referencial teórico é contemplado na parte dois. Depois são expostos os procedimentos metodológicos usados na pesquisa. A quarta parte aborda a análise e discussão dos resultados. Conclui-se com as considerações finais, limitações da pesquisa e recomendações para estudos futuros.

\section{Referencial teórico}

Esta seção descreve uma série de estudos acadêmicos bibliométricos e de rede social realizados em periódicos de diversas áreas ao longo dos últimos anos.

\subsection{Estudos bibliométricos e de redes sociais realizados em periódicos acadêmicos científicos}

A bibliometria é um método de pesquisa da área das Ciências da Informação que utiliza a análise quantitativa de dados para explorar a estrutura intelectual de um determinado campo do conhecimento, e também serve como mecanismo para análise do comportamento dos autores em suas respectivas decisões na construção desse conhecimento científico (LEITE FILHO, 2008), em diferentes tipos de publicações (LIMA; DINIZ; DA SILVA, 2014), em especial em artigos científicos publicados em periódicos (LUCIANI; CARDOSO; BEUREN, 2007).

Nesse contexto, ressalta-se a análise de redes sociais, uma técnica que tem relação com a bibliometria (FRANCISCO, 2011). Sendo assim, entende-se que a análise de redes sociais são conjuntos de contatos que ligam vários atores (NELSON, 1984). Essas relações podem ser formais, informais, fortes ou fracas (GRANOVETTER, 1973). Salienta-se que a densidade é uma das características preponderantes das redes sociais, pois é calculada como proporção do número de relações que existem numa determinada rede social, comparada com o número de interações possíveis totais (PECl, 1999). Sendo assim, a densidade evidencia a extensão na qual a rede está interconectada (LOPES; BALDI, 2009).

Portanto, tanto a análise bibliométrica como a análise de redes sociais (esta podendo ser considerada uma extensão da própria 
bibliometria) são importantes e essenciais para o mapeamento de áreas de conhecimento, que neste estudo se faz representar pela administração pública, à luz da RAP. Para melhor elucidar este trabalho, cabe levantar e discorrer sobre trabalhos bibliométricos e de rede social realizados em periódicos acadêmicos, desenvolvidos no contexto internacional e nacional.

Hoffman e Holbrook (1993) exploraram a análise de citações no Journal of Consumer Research (JCR) durante seus primeiros 15 anos de publicação e, de forma geral, observaram padrões de citações simétricas entre os pesquisadores. Ramos-Rodríguez e Ruíz-Navarro (2004) identificaram as obras que tiveram o maior impacto sobre a estratégia em publicações de administração na revista Strategic Management Journal de 1980 a 2000 e constataram que Michael Porter foi o autor mais evidenciado e que grupos de pesquisadores partilham os mesmos interesses, influenciando nas citações das mesmas referências.

McMillan e Casey (2007) realizaram uma análise bibliométrica da revista Journal British Journal of Industrial Relations entre os anos de 1986 e 2005 e observaram uma maturidade das publicações em 20 anos de pesquisa. De 1980 a 1990, os trabalhos basearam-se na literatura econômica, e a posteriori, na de recursos humanos. Robertson (2008) investigou 658 artigos sobre ética empresarial na revista Strategic Management Journal, no período de 1996 a 2005. O autor observou que o foco sobre ética na empresa nesse periódico tem sido limitado.

Ullah, Butt e Haroon (2008) avaliaram bibliometricamente os artigos do Journal of Ayub Medical College de 1997 a 2006 e concluíram que: o número de artigos publicados por ano variou de 27 a 97; a maioria dos artigos tem de 11 a 20 citações; os autores mais prolíferos contribuíram com sete publicações. Fernandez-Alles e Ramos-Rodríguez (2009) analisaram a estrutura intelectual do tema "gestão de recursos humanos" por meio da técnica da bibliometria no periódico Journal Human Resource Management de 1985 a 2005 e observaram que: as citações mediante livros se destacam em comparação com as de revista; e as publicações com dois ou mais pesquisadores são maioria. 
Ordóñez et al. (2009) fizeram uma análise na Revista de Economia Institucional em seus primeiros dez anos e constataram que: o autor mais profícuo publicou 5 artigos; $82 \%$ dos artigos publicados são oriundos de IES; há certa endogenia entre as IES. Durisin, Calabretta e Parmeggiani (2010) investigaram o Journal of Product Innovation Management por meio da bibliometria entre os anos de 1984 e 2004 e observaram forte impacto das obras mais influentes e a maturidade das pesquisas sobre inovação nos anos de pesquisa.

Borba, Hoeltgebaum e Silveira (2011) analisaram a produção científica do periódico Academy of Management Meeting de 1954 a 2005 e observaram que poucos autores publicam muito e são citados muitas vezes no que tange ao tema empreendedorismo. Ferreira et al. (2011) realizaram uma revisão da literatura para analisar a contribuição de John Dunning para o tema negócios internacionais e pesquisa em estratégia. Para isso, realizaram uma pesquisa bibliométrica de 1980 a 2009 no periódico Strategic Management Journal. Os autores concluíram existir uma contribuição de John Dunning para o tema "negócios internacionais" (verificado pela centralidade das cocitações) e que há uma conexão forte entre os temas "visão baseada em recursos, "custos de transação" e "teoria evolutiva".

Francisco (2011) explorou o acervo da revista RAE-eletrônica por meio da bibliometria de 2002 a 2010. Os principais resultados foram: a média de autores por artigo foi superior a dois; o autor mais profícuo publicou cinco artigos; e a maioria dos artigos foi escrita por autores pertencentes a uma mesma IES. Mascarenhas, Zambaldi e Moraes (2011) investigaram a trajetória do ensino e da pesquisa em administração no Brasil na Revista de Administração de Empresas para discutir desafios atuais quanto à construção da relevância da produção científica. Os resultados revelaram tensões entre pesquisa e tradição da formação profissional; e no que tange à questão da relevância e do impacto do conhecimento produzido, estes sugerem reflexões importantes à comunidade acadêmica. 
Por fim, evidencia-se o trabalho de Bortollossi e Sampaio (2012), que analisaram as publicações da revista Gestão \& Produção de 1999 a 2010. Os principais achados foram: evolução de autores a cada período influenciando na coautoria; centralidade entre os autores e as IES. Percebe-se que a quantidade de trabalhos acadêmicos bibliométricos que investigam revistas acadêmicas científicas vem crescendo. Ainda analisando os artigos, nota-se que grande parte dos trabalhos envolve pesquisas sobre temas específicos e/ou redes de coautoria ou cocitação. Constata-se uma insipiência no que se refere a pesquisas bibliométricas e/ou redes sociais em periódicos nacionais.

Entretanto, é sabido que na literatura nacional já existem várias publicações que trabalharam as duas técnicas juntas ou de maneira separada na área da administração ou afins, no entanto, não é comum identificar essas técnicas de pesquisa explorando um periódico apenas. A RAP abordou as técnicas da bibliometria e rede social analisando diversos temas por meio dos estudos dos autores: Araújo et al. (2011), Andrade et al. (2007,) Braga, Gomes e Ruediger (2008), Brunelli et al. (2010), Capobiango et al. (2011), Hocayen-da-Silva, João (2009), Lopes e Baldi (2009), Martins (2007), Maciel e Machado-da-Silva (2009), Moraes Filho, Barone e Pinto (2011), Pinto e Junqueira (2009), Prates (2009), Quintella et al. (2009), Rossoni, Hocayen-da-Silva e Júnior (2008) e Rossoni e Júnior (2008).

Esta pesquisa realiza um trabalho investigativo mais macro, tentando explorar, por meio da bibliometria e da rede social, o acervo de 2000 até 2011 da RAP, analisando: autoria, produção dos autores e das IES, redes de coautoria e das IES, citações, abordagem metodológica e frequência das palavras.

\section{Procedimentos metodológicos}

Este estudo tem por objetivo explorar as características da produção acadêmica científica da RAP no período de 2000 a 2011. O referido trabalho enfoca e utiliza a bibliometria, uma técnica que mensura o fluxo de informação (FRANCISCO, 2011), apoiada pelos métodos 
quantitativos (BORGES, 2002), matemáticos (ALVARENGA, 1998) e estatísticos (ORTIZ, 2002). Remete-se a metodologias utilizadas pela bibliometria, como o agrupamento bibliográfico e a análise das palavraschave (FRANCISCO, 2011).

A bibliometria, portanto, é uma técnica de pesquisa que analisa publicações em livros, relatórios e artigos (FERREIRA, 2011) para quantificar, analisar e avaliar a produção intelectual científica (RAMOSRODRÍGUEZ; RUÍZ-NAVARRO, 2004) sintetizando-a (CHAMBERS, 2004), sendo adequada ao objetivo deste estudo. Justifica-se o uso da análise bibliométrica por ela conseguir cobrir um período prolongado de tempo, ajudando a identificar informações importantes em journals acadêmicos (NERUR; RASHEED; NATARAJAN, 2008).

A bibliometria desenvolveu-se mediante a elaboração de leis empíricas sobre o comportamento da literatura (EGGHE, 2005). Nesse cenário, é importante conhecer as três leis básicas da bibliometria para o melhor entendimento dos dados. Elas são oriundas respectivamente de três pesquisadores que se destacam por suas importantes descobertas - Bradford, Zipf e Lotka -, sendo as mais comumente utilizadas e relacionadas à produtividade científica (EGGHE, 2005).

A Lei de Bradford mensura o nível de relevância dos periódicos sobre determinada área (ACEDO; CASILLAS, 2005). Já a Lei de Lotka descreve a produtividade e as citações de autores por meio de um modelo de distribuição de tamanho-frequência em um conjunto de pesquisas, evidenciando aspectos de coautoria (AMBONI; CAMINHA; ANDRADE, 2012). E a Lei de Zipf calcula a quantidade de ocorrências das palavras em vários textos, gerando uma lista de terminações de um determinado assunto ou palavra, sendo utilizada para observar qual tema científico é mais evidenciado nos trabalhos (EGGHE, 2005).

Além da bibliometria, os procedimentos realizados envolveram também o exame das análises de rede, mais especificamente de coautorias (NERUR; RASHEED; NATARAJAN, 2008; RAMOSRODRÍGUEZ; RUÍZ-NAVARRO, 2004) e de IES (GONZALO et al., 2009; 
FRANCISCO, 2011) para a melhor compreensão de suas respectivas conectividades.

A rede social é determinada por Wasserman e Faust (1994) como o conjunto de atores e as possíveis interações entre eles em um determinado grupo. Esses atores têm papel preponderante para a difusão de informações, ideias e influências (KEMPE; KLEINBERG; TARDOS, 2005), impactando na propagação e evidenciação de temas e, com isso, no aperfeiçoamento de possíveis áreas do conhecimento.

Tal procedimento é justificado, por entender que o conhecimento científico é construído socialmente (GUARIDO FILHO; MACHADO-DASILVA; GONÇALVES, 2009; ROSSONI; HOCAYEN-DA-SILVA; JÚNIOR, 2008;), influenciado pelos pesquisadores e seus pares, que compõem estruturalmente a rede de relações entre as IES (ROSSONI; HOCAYENDA-SILVA; JÚNIOR, 2008).

Para investigar a produção científica da RAP no período de 2000 a 2011, o que corresponde a um levantamento longitudinal de 12 anos, Os dados foram coletados a partir dos seguintes sites: $<$ http://app.ebape.fgv.br/academico/asp/dsp_rap_edicoes_passadas. asp> e <http://www.scielo.br/scielo.php?script=sci_issues\&pid=00347612\&Ing=pt\&nrm=iso> . O universo da pesquisa foi composto por 669 artigos (Gráfico 1). 
Gráfico 1 - Artigos publicados na Revista de Administração Pública de 2000 a 2011

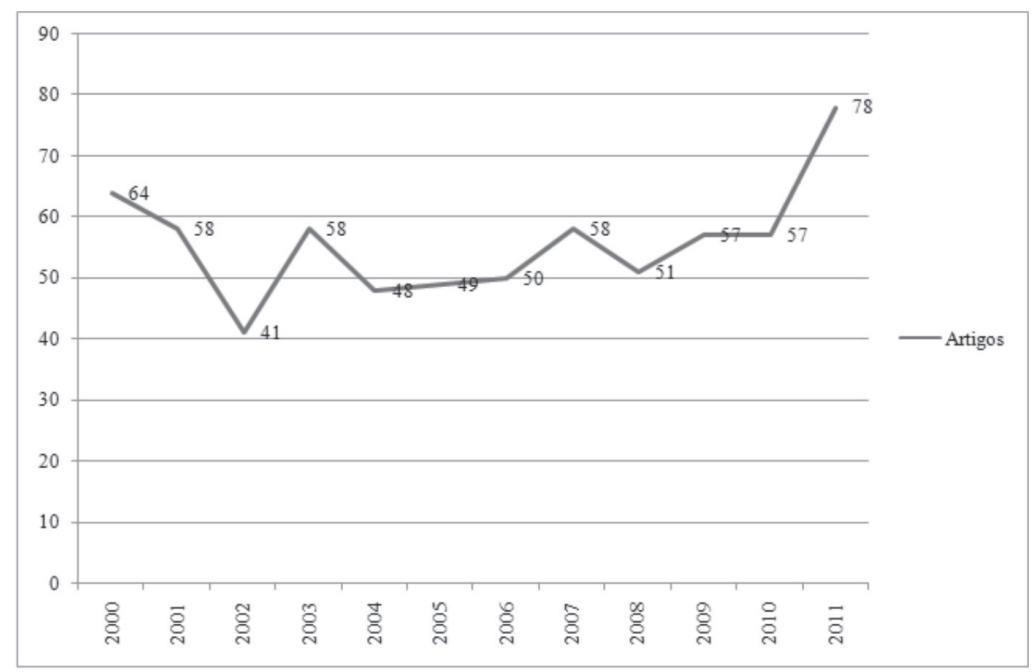

Fonte: Dados da pesquisa (2013)

Com isso, a análise bibliométrica e de rede social do referido artigo foi feita mediante os seguintes indicadores: (I) características de autoria; (II) autores com maior produção; (III) referências mais citadas; (IV) IES com maior produção; (V) rede social dos autores; (VI) rede social das IES; (VII) abordagens metodológicas; e (VIII) frequência das palavras - no título e nas palavras-chave. As informações relevantes e as representações gráficas foram captadas e feitas usando os softwares UCINET 6 for Windows, Microsoft Excel 2007 e Wordle.net.

Ao trabalhar com o Excel 2007, foram tabulados os dados que deram origem aos indicadores mensurados neste texto científico. Essa tabulação foi feita de maneira minuciosa, pegando todos os 669 artigos identificados, de maneira que as informações difundidas e evidenciadas tivessem $100 \%$ de confiabilidade. Em seguida, foram gerados os gráficos que estão representados neste paper. Esclarece-se que nas Figuras $1.1,1.2,1.3,1.4$ e 2.1 não constam os nomes dos autores para evitar poluição visual. No que tange ao software de redes, ou seja, o UCINET 6 , os dados que o compuseram foram originados das mensurações 
anteriormente evidenciadas, usando para compor as matrizes simétricas que foram trabalhadas no referido software de rede. Em seguida, foram geradas, com o auxílio do software NetDraw, as figuras de rede, ou seja, as de coautoria e das IESs, que compõem o UCINET 6. Com relação à figura dos títulos e palavras-chave, foi utilizado o software livre Wordle. net. De maneira geral, foram copiados e colados os títulos e as palavraschave dos 669 textos científicos da RAP, sendo logo em seguida gerada, configurada e formatada a frequência dos títulos e palavras-chave respectivas.

\section{Análise e discussão dos resultados}

A finalidade desta seção foi mobilizar a análise bibliométrica e de rede social dos 669 artigos publicados na RAP.

\subsection{Características de autoria}

O Gráficos 2 apresenta a frequência de artigos de autoria individual; com dois ou mais autores por artigo; e a média de autoria por artigo no período analisado.

Ao analisar o Gráfico 2, verifica-se a predominância de artigos com autoria múltipla, ou seja, com dois ou mais artigos (58,59\%). Destes, os artigos com dois autores se destaca, com 35,28\% do total dos 669 artigos investigados. O gráfico ainda contempla a média de autoria por artigo nos 12 anos analisados, além de mostrar uma evolução, a partir de 2004, da média de autores por publicação, alcançando seu pico em 2011, com 2,54 autores por artigo. 
Gráfico 2 - Autoria dos artigos e média de autoria

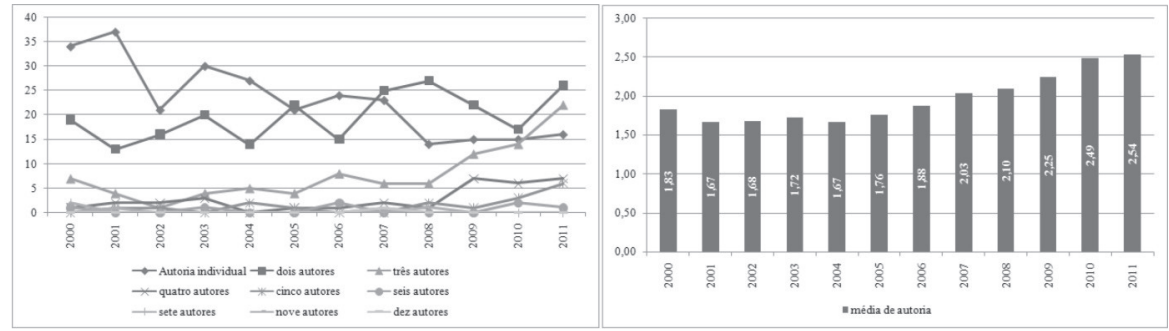

Fonte: Dados da pesquisa (2013)

Em pesquisas em outros periódicos, Fernandez-Alles e RamosRodríguez (2009) e Francisco (2011) também constataram o predomínio de autoria em parceria nos artigos. Tal informação também é vista na pesquisa bibliométrica de Hocayen-da-Silva, Rossoni e Júnior (2008), os quais pesquisaram as temáticas da administração pública e gestão social de 2000 a 2005.

De maneira geral, as informações reveladas no Gráfico 2 ajudam a entender a importância das parcerias em pesquisas, em especial as que ocorreram em 12 anos de estudos na revista ora investigada. As parcerias em estudos acadêmicos são essenciais, pois, através delas, o crescimento e a legitimidade de temas e campos do conhecimento é robustecida.

\subsection{Autores com maior produção}

O Gráfico 3 mostra os autores que mais artigos publicaram durante o período. Jorge Vianna Monteiro é autor o mais profícuo nos 12 anos de pesquisa da RAP, com 63 artigos publicados. Tal resultado é em virtude de a revista manter em todas as suas edições uma seção especial com o título "A Conjuntura das Escolhas Públicas", na qual o autor em destaque coordena e escreve sobre essa temática através de vários papers. Em seguida, vêm T. Diana L. V. A. de Macedo-Soares e Sergio Proença Leitão, com 18 e 15 artigos publicados, respectivamente. 
Gráfico 3 - Autores com maior produção

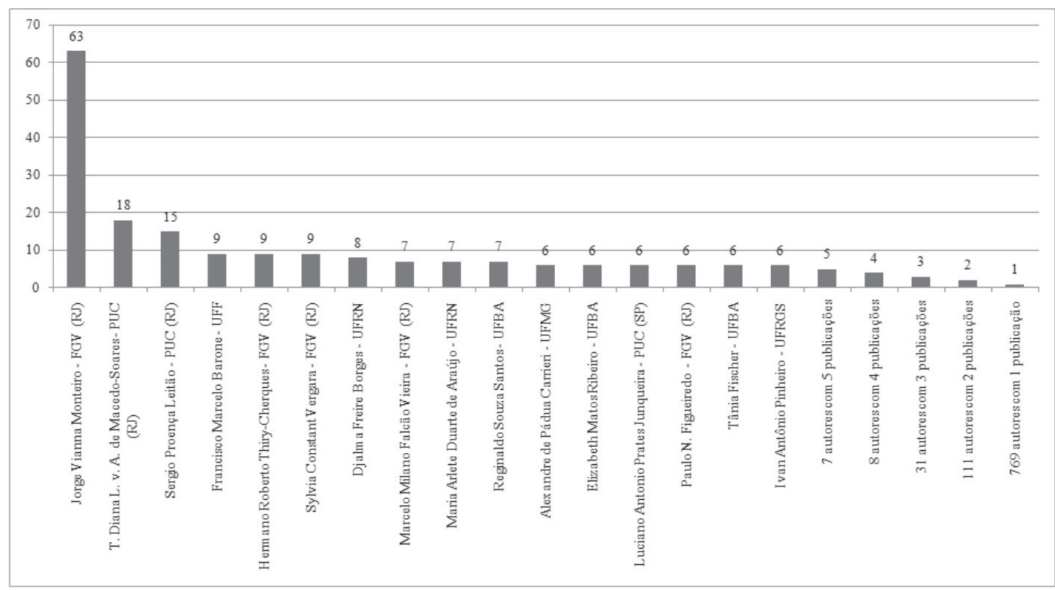

Fonte: Dados da pesquisa (2013)

É importante destacar também os seguintes pesquisadores: Francisco Marcelo Barone, Hermano Roberto Thiry-Cherques e Sylvia Constant Vergara, todos com 9 publicações; com 8 artigos vem Djalma Freire Borges; com 7 artigos aparece os autores: Marcelo Milano Falcão Vieira, Maria Arlete Duarte de Araújo e Reginaldo Souza Santos; e com 6 papers publicados estão os pesquisadores: Alexandre de Pádua Carrieri, Elizabeth Matos Ribeiro, Luciano Antonio Prates Junqueira, Paulo N. Figueiredo, Tânia Fischer e Ivan Antônio Pinheiro.

Em suma, dos 942 autores, 16 publicaram de 6 a 63 artigos; 46 publicaram de 5 a 3 artigos; 111 publicaram 2 artigos; e a maioria, ou seja, 769 autores, publicou apenas 1 artigo. Essa informação vai ao encontro da Lei de Lotka, a qual enfatiza que poucos pesquisadores publicam muito e muitos pesquisadores publicam pouco (AMBONI; CAMINHA; ANDRADE, 2012), mostrando a relevância desses poucos para o periódico ora estudado.

\subsection{Referências mais citadas}

O Gráfico 4 mostra a frequência dos pesquisadores mais citados nos 669 artigos publicados. O autor Monteiro, J. V. foi o mais citado, com 
159 citações. Bresser-Pereira, L. C. é o segundo mais citado (122). Eles são seguidos por Macedo-Soares, T. D. L. V. A. (73), Bourdieu, P. (72), Spink, P. K. (67), Mintzberg, H. (62), Porter, M. (60), Foucault, M. (59), Vergara, S. C. (59), Leitão, S. P. (57), Clegg, S. R. (55), Morgan, G. (53), Hardy, C. (52), Weber, M. (52) e Yin, R. K. (52).

Gráfico 4 - Referências mais citadas

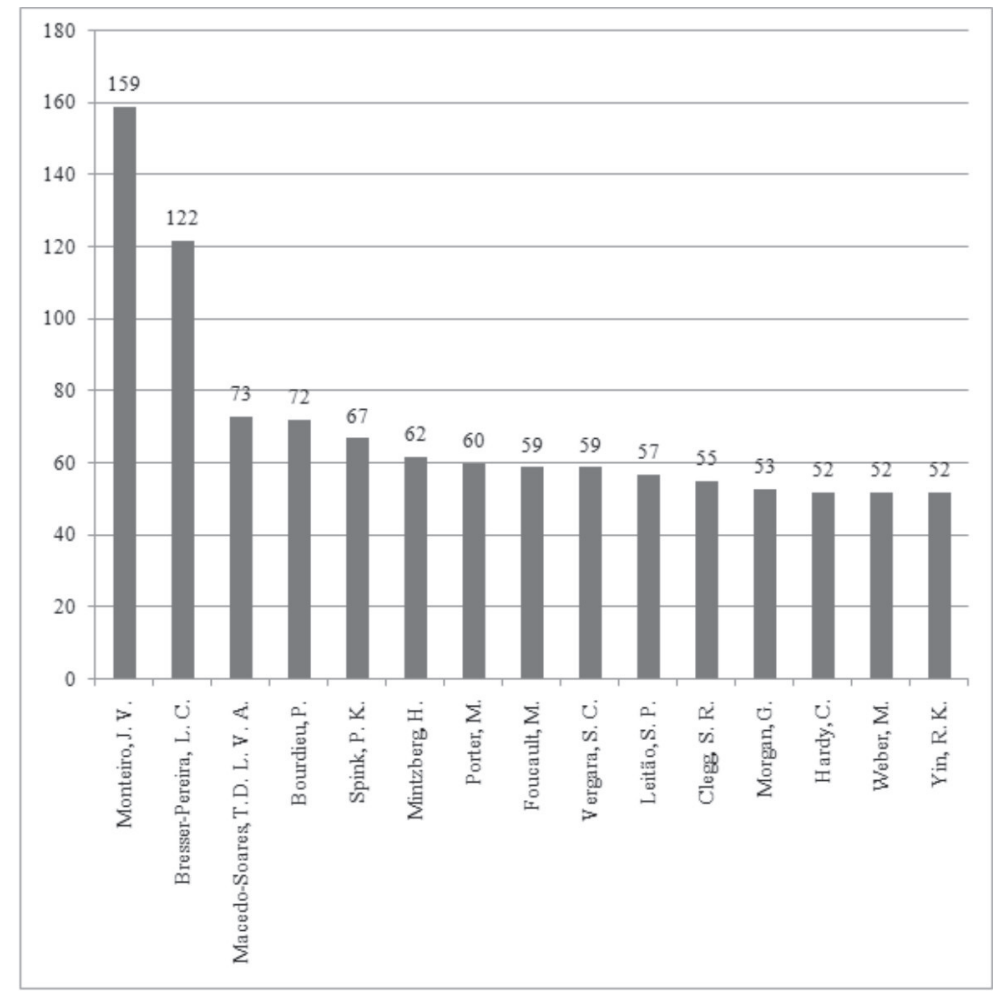

Fonte: Dados da pesquisa (2013)

Tal resultado está alinhado com a Lei de Lotka, a qual parte da premissa de que alguns pesquisadores publicam muito e por isso são mais citados do que outros que publicam menos. Isso é confirmado por meio de outras pesquisas com o mesmo foco: Borba, Hoeltgebaum e Silveira (2011), Ferreira (2011), Nerur, Rasheed e Natarajan (2008), 
Moraes Filho, Barone e Pinto (2011), Ramos-Rodríguez e Ruíz-Navarro (2004).

Em suma, analisar as citações permite entender quais obras têm maior influência sobre a pesquisa existente, ajudando pesquisadores novos a terem um norte de quem e quais obras devem pesquisar e referenciar. Essa iniciativa impacta positivamente em futuros estudos, propiciando uma maior qualidade a esses trabalhos, ao citar estudiosos que se destacam na área, por meio de pesquisas recentes e/ou mediante manuscritos seminais, que dão maior legitimidade ao estudo que está sendo realizado e será publicado em congressos e periódicos da área de administração.

\subsection{IES com maior produção}

O Gráfico 5 apresenta as 20 IES com maior volume de publicações na revista RAP, de um total de 193 IES.

\section{Gráfico 5 - IES com maior produção}

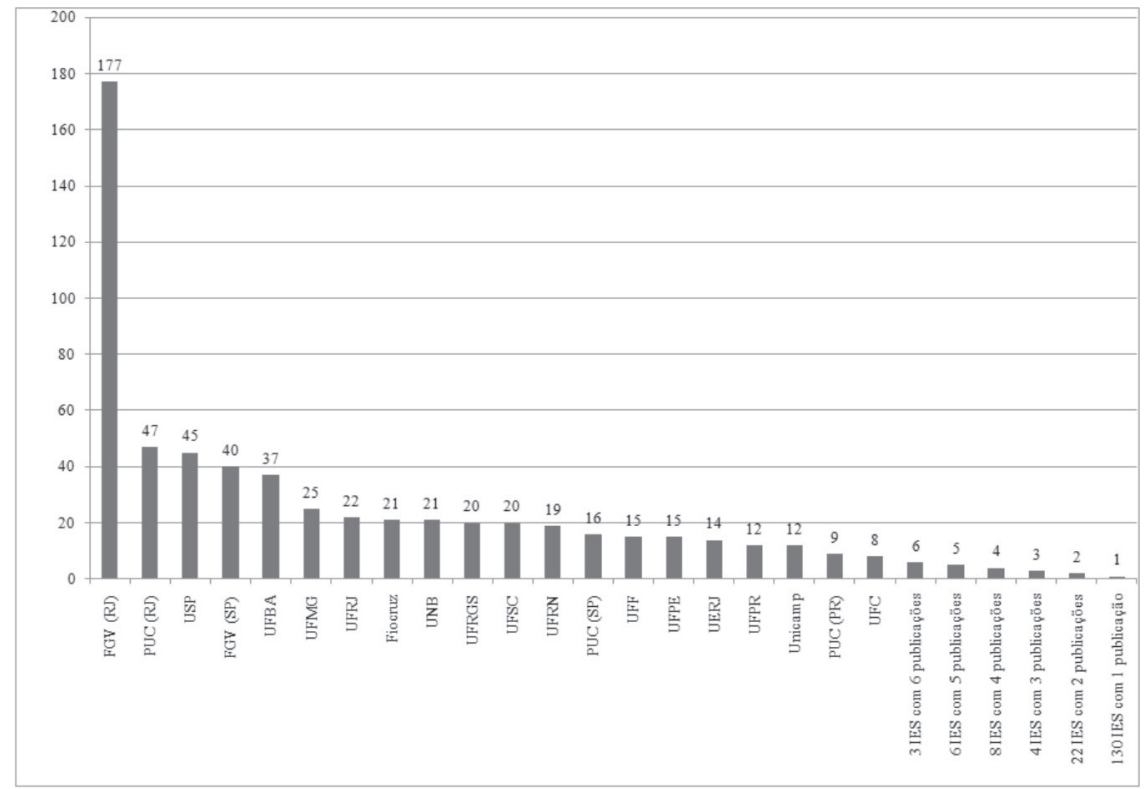

Fonte: Dados da pesquisa (2013) 
Analisando o desempenho das IES segundo as suas participações na autoria das publicações, tem-se a FGV (RJ) com 177 artigos publicados. Na sequência, a PUC (RJ), com 47 publicações, USP (45), FGV (SP) (40), UFBA (37), UFMG (25), UFRJ (22), Fiocruz (21), UNB (21), UFRGS (20), UFSC (20), UFRN (19), PUC (SP) (16), UFF (15), UFPE (15), UERJ (14), UFPR (12), Unicamp (12), PUC (PR) (9) e UFC (15). Hocayen-da-Silva, Rossoni e Júnior (2008), Rossoni, Hocayen-daSilva e Júnior (2008) e Capobiango et al. (2011), em seus respectivos estudos, confirmam a importância dessas IES para a área pública, por meio dos artigos publicados por elas.

Nota-se que das 193 IES, 20 publicaram 8 ou mais artigos, 43 tiveram de 2 a 6 publicações, e a maioria (130) publicou apenas 1 artigo no período investigado. De maneira geral, 32,64\% das IES publicaram mais de uma vez e $67,36 \%$ publicaram apenas uma vez. Ainda cabe frisar que das 193 IES, 47 são oriundas de outros países, são eles: Estados Unidos (10), Chile (4), Portugal (7), Inglaterra (5), Argentina (5), Alemanha (3), Canadá (3), Espanha (3), Holanda (2), Austrália (2), Uruguai (1), Rússia (1) e Malásia (1 IES). Ou seja, 75,65\% das IES representadas neste estudo são nacionais e $24,35 \%$, de outros países.

\subsection{Rede social dos autores}

As Figuras 1, 2, 3 e 4 descrevem a evolução das redes de coautoria dos 669 artigos a cada 3 anos, ou seja, em 4 triênios investigados na RAP, perfazendo 12 anos de pesquisa. 
Figura 1: Rede de coautoria de 2000 a 2002

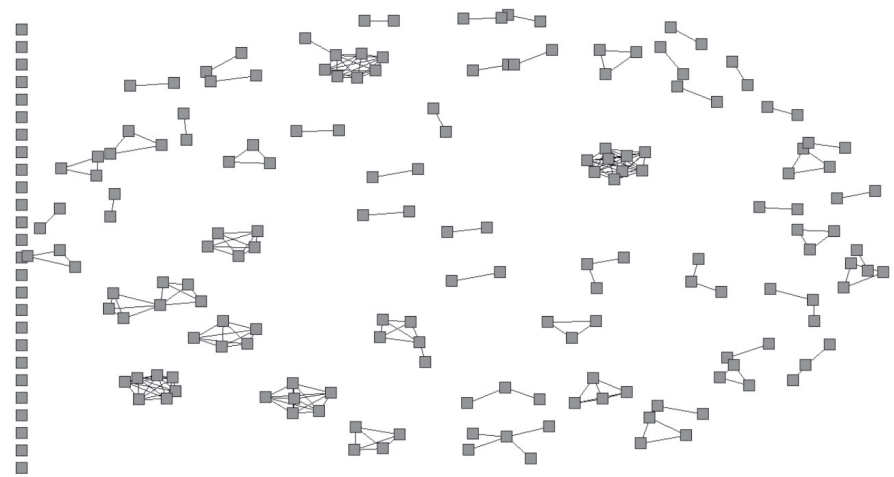

Fonte: Dados da pesquisa (2013)

A Figura 1.1 evidencia a rede com 191 autores entre os anos de 2000 e 2002, com uma densidade de 0,0091, sugerindo que somente $0,91 \%$ de suas relações estão sendo efetivamente trabalhadas. Esse percentual é pequeno e influencia na socialização e evidenciação das pesquisas da RAP, e, consequentemente, no campo do conhecimento da administração, em especial da área pública. É certo que a quantidade de interações e a robustez da densidade creditam uma maior amplitude de ideias e gerações de estudos, fomentando a disseminação de pensamentos e o alargamento de parcerias entre os pesquisadores que publicam nessa revista.

Figura 2 - Rede de coautoria de 2003 a 2005

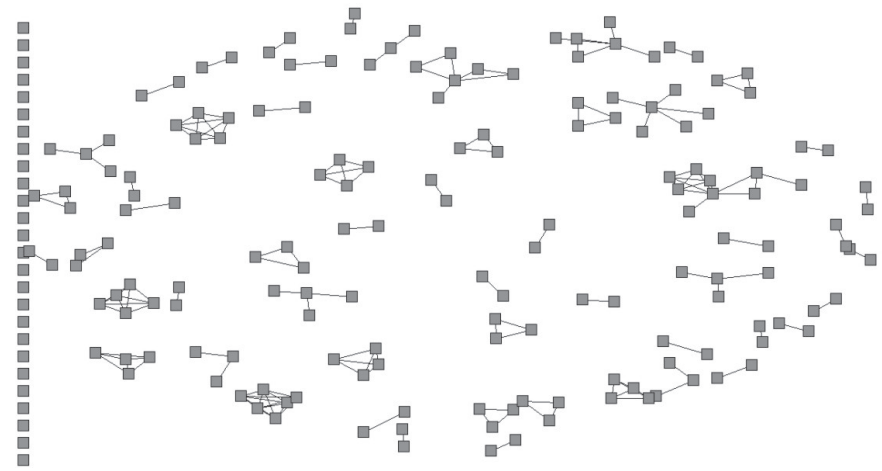

Fonte: Dados da pesquisa (2013) 
A Figura 2 se configura com uma densidade ainda menor: $0,68 \%$ de suas interações realizadas - pouco, ao se constatarem 188 autores participando dessa rede social. Observa-se, com isso, que a quantidade de autores (três a menos que a Figura 1) interagiu ainda menos. Tal fato pode ser em virtude da consolidação de grupos de estudo ou do surgimento de outros, com poucos articulistas compondoos, inviabilizando uma rede mais densa.

Figura 3 - Rede de coautoria de 2006 a 2008

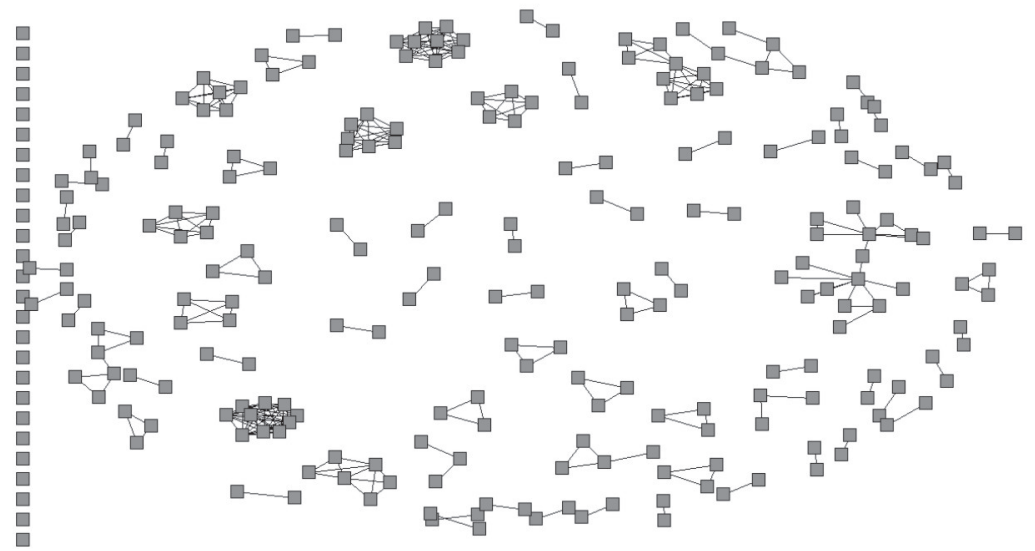

Fonte: Dados da pesquisa (2013)

A Figura 3 contempla 226 autores, ou seja, 44 a mais do que o triênio anterior. Contudo, quando se descreve a densidade dessa rede $(0,0087)$, verifica-se uma similaridade com os triênios anteriores. Apesar de a quantidade de pesquisadores ser maior, a densidade foi quase parecida com a evidenciada na Figura 1. Isso pode ser devido à quantidade de articulistas que publicaram sozinhos e aos grupos de pesquisa não terem se relacionado uns com os outros. 
Figura 4 - Rede de coautoria de 2009 a 2011

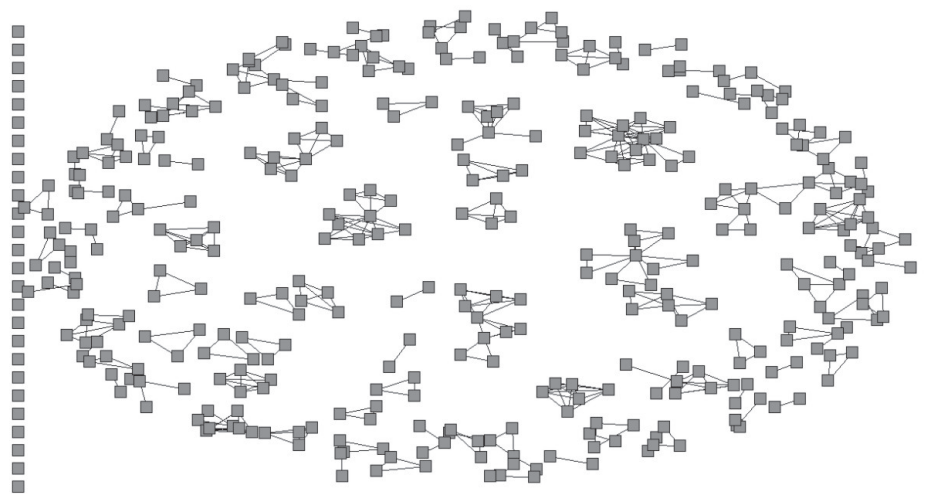

Fonte: Dados da pesquisa (2013)

Ao analisar a Figura 4, constata-se uma maior quantidade de autores nesse triênio (337) em comparação aos anteriores. Esse crescimento foi influenciado pela quantidade de artigos publicados (78) no ano de 2011. Porém, tal fato não impactou no crescimento da densidade da rede, a qual é descrita com $0,60 \%$ da capacidade de interação, mostrando que os laços de colaboração dos pesquisadores nos triênios investigados ainda é muito aquém do que se espera, inviabilizando uma maior densidade.

Entretanto, é importante salientar que os laços fracos têm um papel especial na oportunidade de um ator ter mobilidade, e que há uma tendência estrutural para aqueles que são apenas fracamente ligados de terem melhor acesso a informações (GRANOVETTER, 1973 e 1983), contribuindo para o crescimento de futuras interações por parte dos pesquisadores e suas respectivas instituições de ensino superior.

\subsection{Rede social das IES}

As Figuras 5 e 6 mostram a rede das 193 IES investigadas neste estudo e as principais redes sociais das IES nos 669 artigos analisados.

Analisando a Figura 5, observam-se três blocos divididos: o primeiro, com IES sem parceria; o segundo, o IES com parceria mais dispersas; e o terceiro, com um aglomerado de IES maior, representado 
pela Figura 6. Ainda é importante salientar que a Figura 5 tem uma densidade de rede baixa $(0,0140)$.

Essas informações vão ao encontro dos dados vistos nas Figuras 1 a 4 . Pode-se entender com isso que a densidade de rede dos autores influenciou na densidade de rede das IES investigadas neste estudo. Isso é corroborado através do estudo de Bortollossi e Sampaio (2012).

Figura 5 - Rede social das IES
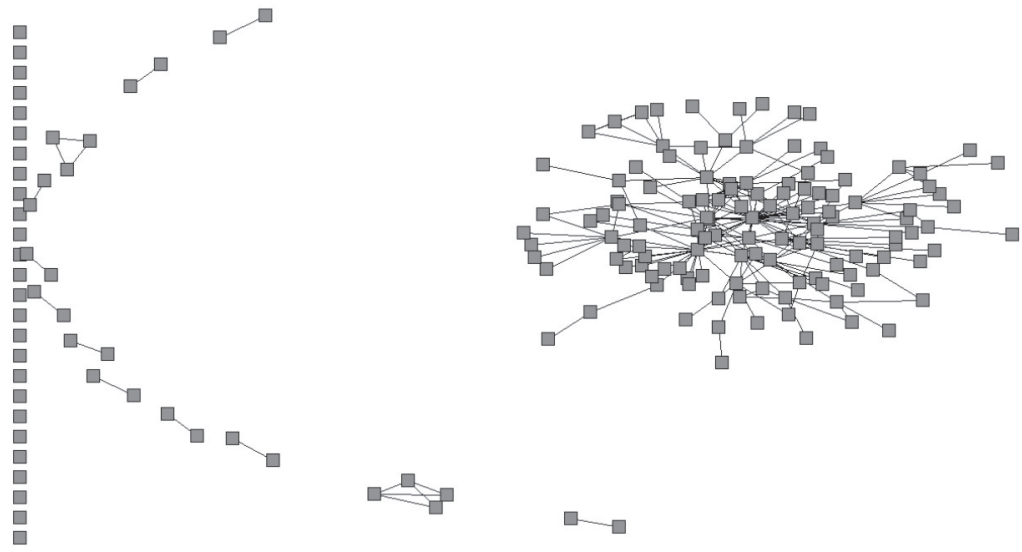

Fonte: Dados da pesquisa (2013)

A Figura 6 representa a rede de colaboração entre as instituições, utilizando a centralidade de grau (simples) de cada IES como informação de elevação. De acordo com Francisco (2011), essa análise permite que facilmente visualize a configuração de rede e seus atores mais relevantes em parceria.

Com isso, ressalta-se a importância e a influência da FGV (RJ), a IES mais central desta pesquisa no contexto da RAP, seguida da USP, UFRJ, UNB, UFSC, FGV (SP), UFRGS, Fiocruz, UFBA e UFPE. Tal resultado remete ao que foi contemplado e descrito no Gráfico 5, mostrando uma relação das IES que mais publicam com as mais centrais neste estudo. 
Figura 6 - Principais redes sociais das IES

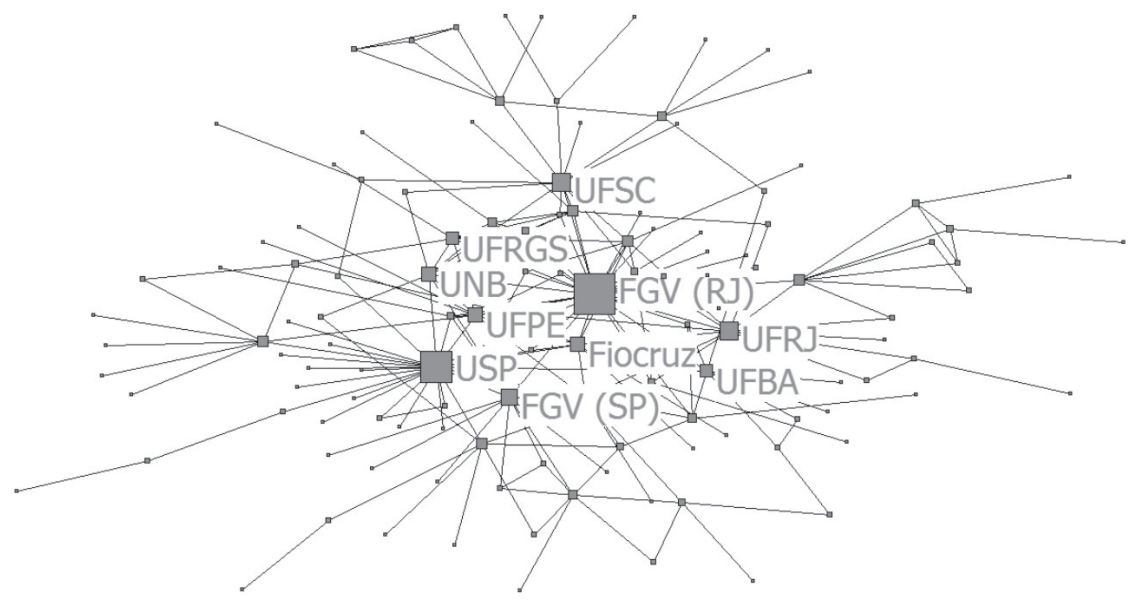

Fonte: Dados da pesquisa (2013)

Em suma, as instituições com muitos artigos apresentam também alta centralidade de grau (número de arestas do nó), indicando a grande preferência por coautorias para as instituições mais frequentes no acervo (FRANCISCO, 2011) do periódico ora estudado. Dessas IES, realçamse a FGV (RJ), à qual a RAP pertence, e a USP, que é a maior instituição acadêmica de pesquisa do Brasil, não só da área de administração pública como também em outras áreas, como governança corporativa (RIBEIRO et al., 2012) e controladoria e contabilidade gerencial (RIBEIRO, 2013).

\subsection{Abordagens metodológicas}

O Gráfico 6 evidencia as abordagens de pesquisa usadas nos 669 artigos analisados. 
Gráfico 6 - Abordagens metodológicas

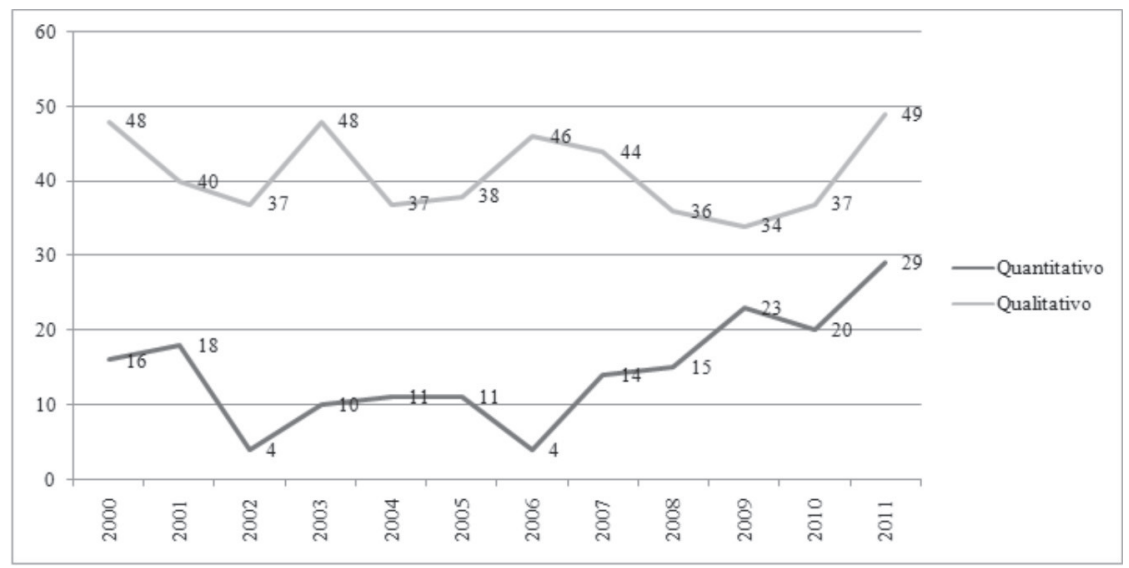

Fonte: Dados da pesquisa (2013)

Nessa distribuição dos estudos do periódico RAP, destaca-se a abordagem qualitativa. Os dados mostram que grande parte dos 669 trabalhos vem sendo investigada pela abordagem qualitativa (em 494 estudos), o que representa aproximadamente $74 \%$ das pesquisas. Tal fato representa um interesse amplo dos pesquisadores por esse método de pesquisa.

\subsection{Frequência das palavras: no título e nas palavras-chave}

As Figuras 7 e 8 contemplam respectivamente a frequência das palavras evidenciadas nos títulos e nas palavras-chave nos 669 artigos da RAP entre 2000 a 2011. Essa nuvem de palavras é uma maneira de visualização de dados linguísticos que mostra a frequência com que as palavras aparecem em determinado cenário (FRANCISCO, 2011). 
Figura 7 - Frequência nos títulos

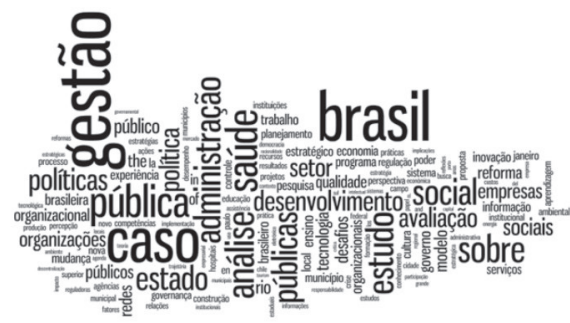

Fonte: Dados da pesquisa (2013)
Figura 8 - Frequência nas palavras-chave

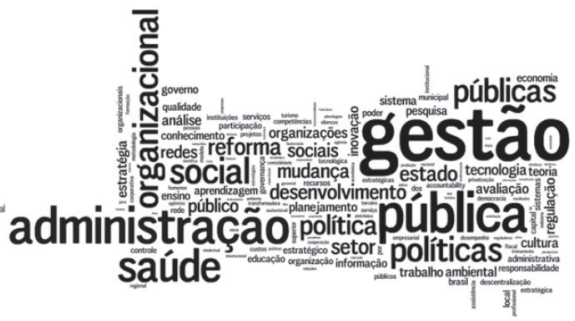

Fonte: Dados da pesquisa (2013)

Observa-se que, nos títulos, as palavras que se destacam são: gestão, Brasil, caso e pública. No que tange às palavras-chave, destacam-se: gestão, pública, administração, saúde e políticas. Notase certa similaridade entre as duas figuras: o destaque das palavras "gestão" e "pública". Remete-se à Lei de Zipf, que calcula a frequência de ocorrências das palavras, com o intuito de criar e evidenciar o tema científico mais contemplado nas pesquisas (EGGHE, 2005).

\section{Considerações finais}

Este trabalho explorou a produção acadêmica científica da RAP no período de 2000 a 2011. Para tanto, efetuou-se uma análise bibliométrica e de rede social em uma amostra de 669 artigos. Constatou-se que a maioria dos artigos publicados é em parceria (58,59\%). Observou-se que os autores Jorge Vianna Monteiro, T. Diana L. V. A. de MacedoSoares e Sergio Proença Leitão são os pesquisadores mais profícuos e a FGV (RJ) é a IES que mais publicou artigos nesses 12 anos de pesquisa, sendo também a com maior centralidade de grau.

No entanto, é bom ressaltar a diversidade de autores (942) e IES (193) envolvida na publicação dos 669 artigos estudados em 12 anos de pesquisa. Esse número elevado de autores e IES são preponderantes e inerentes a periódicos que se preocupam com a busca pela diversificação e socialização de opiniões e pontos de vista. 
Com relação às citações, contemplam-se os autores Monteiro, J. V., Bresser-Pereira, L. C., Macedo-Soares, T. D. L. V. A., Bourdieu, P. e Spink, P. K. como os mais citados. Salienta-se que os autores Jorge Vianna Monteiro, T. Diana L. V. A. de Macedo-Soares, Sergio Proença Leitão e Sylvia Constant Vergara, além de serem também os pesquisadores mais referenciados nas citações (Gráfico 4), destacam-se como autores mais profícuos (Gráfico 3). Justifica-se tal resultado pelo hábito da autocitação, em que o pesquisador referencia suas pesquisas anteriores já publicadas, quando intenciona aproveitar ideias ou mesmo trechos desses trabalhos para construção de novas ideias e argumentos (SARAIVA; CARRIERI, 2009).

Conclui-se que o acervo dos 669 artigos investigados da RAP reflete o universo da produção acadêmica da área de administração pública, ajudando a desenvolver, disseminar e socializar a área por meio de artigos científicos publicados na literatura acadêmica nacional. Este artigo limitou-se aos 12 anos de publicação da RAP. Com isso, sugere-se, para futuros estudos, estender essa análise, iniciando a partir do Volume 1 do referido periódico. Sugere-se também o aprofundamento do estudo de redes sociais por meio de outros indicadores, o que aperfeiçoaria os resultados deste trabalho.

\section{Referências}

ACEDO, F. J.; CASILLAS, J. C. Current paradigms in the international management field: an author co-citation analysis. International Business Review, EUA, v. 14, p. 619-639, out., 2005.

ALVARENGA, L. Bibliometria e arqueologia do saber de Michael Foucault - traços de identidade teórico-metodológica. Ciência da Informação, Brasília, v. 27, n. 3, p. 1-9, set.,1998.

AMBONI, N.; CAMINHA, D. O.; ANDRADE, R. O. B. de. Produção acadêmica em teoria neo-institucional no Brasil: 1990 a 2010. Revista Gestão e Planejamento, Salvador, v. 13, n. 2, p. 212-231, maio/ago., 2012. 
ANDRADE, E. L. G.; ACÚRCIO, F. de A.; GHERGHIGLIA, M. L.; BELISÁRIO, S. A.; JÚNIOR, A. A. G.; SZUSTER, D. A. C.; FALEIROS, D. R.; TEIXEIRA, H. V.; SILVA, G. D. da; TAVEIRA, T. S. Pesquisa e produção científica em economia da saúde no Brasil. Revista de Administração Pública, Rio de Janeiro, v. 41, n. 2, p. 211-235, mar./ abr., 2007.

ARAÚJO, U. P.; ANTONIALLI, L. M.; BRITO, M. J. de; GOMES, A. F.; OLIVEIRA, R. F. de. Consubstanciação da imagem da Embrapa no campo científico. Revista de Administração Pública, Rio de Janeiro, v. 45, n. 3, p. 775-811, maio/jun., 2011.

BORBA, M. L. de; HOELTGEBAUM, M.; SILVEIRA, A. A produção científica em empreendedorismo: análise do Academy of Management Meeting: 1954-2005. Revista de Administração Mackenzie, São Paulo, v. 12, n. 2, p. 169-206, mar./abr., 2011.

BORGES, P. C. R. Métodos quantitativos de apoio à bibliometria: a pesquisa operacional pode ser uma alternative? Ciência da Informação, Brasília, v. 31, n. 3, p. 5-17, set./dez., 2002.

BORTOLLOSSI, L. N.; SAMPAIO, M. A produção acadêmica publicada na revista Gestão \& Produção de 1999 a 2010: tendências e direções para pesquisas futuras. Gestão \& Produção, São Carlos, v. 19, n. 1, p. 189-201, jan./mar., 2012.

BRAGA, M. J. da C.; GOMES, L. F. A. M.; RUEDIGER, M. A. Mundos pequenos, produção acadêmica e grafos de colaboração: um estudo de caso dos Enanpads. Revista de Administração Pública, Rio de Janeiro, v. 42, n. 1, p. 133-154, jan./fev., 2008.

BRUNELLI, M. de Q.; MACEDO-SOARES, T. D. L. van A. de; ZOUAIN, D. M.; BORGES, A. P. Scientific research in tourism: review of the literature from 2005 to 2009. Revista de Administração Pública, Rio de Janeiro, v. 44, n. 5, p. 1225-1240, set./out., 2010.

CAMPOS, A. M. de S. M.; COSTA, I. de S. A. da. Espaços e caminhos para a pesquisa em administração: estimulando a prática da reflexividade. 
Revista de Administração Pública, Rio de Janeiro, v. 41, n. especial, p. 37-48, nov./dez., 2007.

CAPOBIANGO, R. P.; SILVEIRA, S. de F. R.; ZERBATO, C.; MENDES, A. C. A. Análise das redes de cooperação científica através do estudo das coautorias dos artigos publicados em eventos da Anpad sobre avaliação de políticas públicas. Revista de Administração Pública, Rio de Janeiro, v. 45, n. 6, p. 1869-1890, nov./dez., 2011.

CHAMBERS, E. A. An introduction to meta-analysis with articles from the journal of educational research (1992-2002). The Journal of Educational Research, EUA, v. 98, n. 1, p. 35-44, set./out., 2004.

DURISIN, B.; CALABRETTA, G.; PARMEGGIANI, V. The intellectual structure of product innovation research: a bibliometric study of the Journal of Product Innovation Management, 1984-2004. Journal of Product Innovation Management, EUA, v. 27, p. 437-451, maio, 2010.

EGGHE, L. Zipfian and lotkaian continuous concentration theory. Journal of the American Society for Information Science and Technology, EUA, v. 56, n. 9, p. 935-945, jul., 2005.

FERNANDEZ-ALLES, M.; RODRÍGUEZ-RAMOS, A. Intellectual structure of human resources management research: a bibliometric analysis of the journal human resource management, 1985-2005. Journal of the American Society for Information Science and Technology, EUA, v. 60, n. 1, p. 161-175, jan., 2009.

FERREIRA, M. P. A bibliometric study on ghoshal's managing across borders. The Multinational Business Review, Reino Unido, v. 19, n. 4, p. 357-375, nov., 2011.

FERREIRA, M. P. et al. John Dunning's influence in international business/ strategy research: a bibliometric study in the strategic management journal. Journal of Strategic Management Education, Irlanda, v. 7, n. 2, p. 1-24, abr./jun., 2011. 
FRANCISCO, E. de R. RAE-eletrônica: exploração do acervo à luz da bibliometria, geoanálise e redes sociais. Revista de Administração de Empresas, São Paulo, v. 51, n. 3, p. 280-306, maio/jun., 2011.

GRANOVETTER, M. S. The strength of weak ties: a network theory revisited. Sociological Theory, EUA, v. 1, n. 1, p. 201-233, dez., 1983.

GRANOVETTER, M. S.. The strength of weak ties. American Journal of Sociology, EUA, v. 78, n. 6, p. 360-380, maio, 1973.

GUARIDO FILHO, E. R.; MACHADO-DA-SILVA, C. L.; GONÇALVES, S. A. Organizational institutionalism in the academic field in Brazil: social dynamics and networks. Brazilian Administration Review, Curitiba, v. 6, n. 4, p. 299-315, out./dez., 2009.

HOCAYEN-DA-SILVA, A. J.; ROSSONI, L.; JÚNIOR, I. F. Administração pública e gestão social: a produção científica brasileira entre 2000 e 2005. Revista de Administração Pública, Rio de Janeiro, v. 42, n. 4, p. 655-680, jul./ago., 2008.

HOFFMAN, D. L.; HOLBROOK, M. B. The intellectual structure of consumer research: a bibliometric study of author cocitations in the first 15 years of the journal of consumer research. Journal of Consumer Research, EUA, v. 19, p. 505-517, mar., 1993.

JABBOUR, C. J. C.; SANTOS, F. C. A.; BARBIERI, J. C. Gestão ambiental empresarial: um levantamento da produção científica brasileira divulgada em periódicos da área de administração entre 1996 e 2005. Revista de Administração Contemporânea, Curitiba, v. 12, n. 3, p. 689-715, julh./set., 2008.

JOÃO, B. do N. Redes em subsidiárias de multinacionais: um estudo de caso com análise de redes sociais de inventores e patentes. Revista de Administração Pública, Rio de Janeiro, v. 43, n. 5, p. 1037-1066, set./ out., 2009.

D. KEMPE, J.; KLEINBERG, E.; TARDOS, Influential nodes in a diffusion model for social networks". In: Proc. International Colloquium 
on Automata, Languages and Programming, 32, 2005, Lisboa, Portugal, Revista ICALP, Lisboa, Portugal, Jul. 2005, pp. 1127-1138.

LEITE FILHO, G. A. Padrões de produtividade de autores em periódicos e congressos na área de contabilidade no Brasil: um estudo bibliométrico. Revista de Administração Contemporânea, Curitiba, v. 12, n. 2, p. 533-554, abr./jun., 2008.

LIMA, F. C.; DINIZ, J. R.; DA SILVA, D. M. Perfil de produção científica em contabilidade: um comparativo entre os periódicos Contabilidade Vista \& Revista e Universo Contábil, no período de 2006 a 2010. Revista de Administração, Contabilidade e Economia, Joaçaba, v. 12, n. 2, p. 607-676, jul./dez., 2014.

LIMA, J. C. J.; CARDOSO, N. J.; BEUREN, I. M. Inserção da Controladoria em Artigos de Periódicos Nacionais Classificados no Sistema Qualis da Capes. Revista Contabilidade Vista \& Revista, Belo Horizonte, v. 18, n. 1, p. 11-26, jan./mar., 2007.

LOPES, F. D.; BALDI, M. Redes como perspectiva de análise e como estrutura de governança: uma análise das diferentes contribuições. Revista de Administração Pública, Rio de Janeiro, v. 43, n. 5, p. 1007 1035, set./out., 2009.

MACIEL, C. de O.; MACHADO-DA-SILVA, C. L. Práticas estratégicas em uma rede de congregações religiosas: valores e instituições, interdependência e reciprocidade. Revista de Administração Pública, Rio de Janeiro, v. 43, n. 6, p. 1251-1278, nov./dez., 2009.

MARTINS, P. E. M. Revisitando os clássicos da RAP. Revista de Administração Pública, Rio de Janeiro, v. 41, n. especial, p. 49-65, nov./dez., 2007.

MASCARENHAS, A. O.; ZAMBALDI, F.; MORAES, E. A. de. Rigor, relevância e desafios da academia em administração: tensões entre pesquisa e formação profissional. Revista de Administração de Empresas, São Paulo, v. 51, n. 3, p. 265-279, maio/jun., 2011. 
MCMILLAN, G. S.; CASEY, D. L. Research note: identifying the invisible colleges of the british journal of industrial relations: a bibliometric and social network approach. British Journal of Industrial Relations, Reino Unido, v. 45, n. 4, p. 815-828, nov., 2007.

MORAES FILHO, A. C. T. de; BARONE, F. M.; PINTO, M. de O. A produção científica em empresas familiares: um enfoque conceitual. Revista de Administração Pública, Rio de Janeiro, v. 45, n. 6, p. 19711991, novembro/dezembro, 2011.

MOTTA, P. R. A modernização da administração pública brasileira nos últimos 40 anos. Revista de Administração Pública, Rio de Janeiro, Edição Especial Comemorativa, p. 87-96, novembro/dezembro, 2007.

NELSON, R. O uso da análise de redes sociais no estudo das estruturas organizacionais. Revista de Administração de Empresas, São Paulo, v. 24, n. 4, p. 150-157, outubro/dezembro, 1984.

NERUR, S. P.; RASHEED, A. A.; NATARAJAN, V. The intellectual structure of the strategic management field: an author co-citation analysis. Strategic Management Journal, EUA, v. 29, p. 319-336, março, 2008.

OLIVEIRA, F. B. de; SAUERBRONN, F. F. Trajetória, desafios e tendências no ensino superior de administração e administração pública no Brasil: uma breve contribuição. Revista de Administração Pública, Rio de Janeiro, v. 41, n. especial, p. 149-170, novembro/dezembro, 2007.

ORDÓÑEZ, G. M.; HERNÁNDEZ, A. B.; HERNÁNDEZ, C.; MÉNDEZ, C. Análisis bibliométrico de la revista de economía institucional en sus primeros diez años. Revista de Economía Institucional, Colômbia, v. 11, n. 20, p. 309-353, setembro, 2009.

ORTIZ, L. C. Ferramentas alternativas para monitoramento e mapeamento automatizado do conhecimento. Ciência da Informação, Brasília, v. 31, n. 3, p. 66-76, setembro/dezembro, 2002. 
PECl, A. Emergência e proliferação de rede organizacionais: marcando mudança no mundo de negócios. Revista de Administração Pública, Rio de Janeiro, v. 33, n. 6, p. 7-24, 1999.

PINTO, A. M. G.; JUNQUEIRA, L. A. P. Relações de poder em uma rede do terceiro setor: um estudo de caso. Revista de Administração Pública, Rio de Janeiro, v. 43, n. 5, p. 1091-1116, setembro/outubro, 2009.

PRATES, A. A. P. Redes sociais em comunidades de baixa renda: os efeitos diferenciais dos laços fracos e dos laços fortes. Revista de Administração Pública, Rio de Janeiro, v. 43, n. 5, p. 1117-1146, setembro/outubro, 2009.

QUINTELLA, R. H.; FREITAS, E. J. da S. M. de; VENTURA, A. C.; SANTOS, M. A.; ANTONIO, L. Q. Network dynamics in scientific knowledge acquisition: an analysis in three public universities in the state of Bahia. Revista de Administração Pública, Rio de Janeiro, v. 43, n. 6, p. 1279-1314, novembro/dezembro, 2009.

RAMOS-RODRÍGUEZ, A. R.; RUÍZ-NAVARRO, J. Changes in the intellectual structure of strategic management research: a bibliometric study of the strategic management journal, 1980-2000. Strategic Management Journal, EUA, v. 25, p. 981-1004, outubro, 2004.

REVISTA DE ADMINISTRAÇÃO PÚBLICA (RAP). Escola Brasileira de Administração Pública e de Empresas (FGV/EBAPE). Disponível em: <http://ebape.fgv.br/publicacoes/rap>. Acesso em: 21 jul.2012.

RIBEIRO, H. C. M. Contribuição do Congresso USP ao estudo da área temática controladoria e contabilidade gerencial: uma bibliometria. Revista de Administração, Contabilidade e Economia, Joaçaba, v. 12, n. 2, p. 709-746, julho/dezembro, 2013.

RIBEIRO, H. C. M.; MACHADO JUNIOR, C.; SOUZA, M. T. S. de; CAMPANÁRIO, M. de A.; CORRÊA, R. Governança Corporativa: Um Estudo Bibliométrico da Produção Científica das Dissertações e Teses 
Brasileiras. Contabilidade, Gestão e Governança, Brasília, v. 15, n. 3, p. 52-70, setembro/dezembro, 2012.

ROBERTSON, C. J. An analysis of 10 years of business ethics research in Strategic Management Journal: 1996-2005. Journal of Business Ethics, EUA, v. 80, p. 745-753, junho, 2008.

ROSSONI, L.; HOCAYEN-DA-SILVA, A. J. Cooperação entre pesquisadores da área de administração da informação: evidências estruturais de fragmentação das relações no campo científico. Revista de Administração da USP, São Paulo, v. 43, n. 2, p. 138-151, abril/ junho, 2008.

ROSSONI, L.; HOCAYEN-DA-SILVA, A. J.; JÚNIOR, I. F. Aspectos estruturais da cooperação entre pesquisadores no campo de administração pública e gestão social: análise das redes entre instituições no Brasil. Revista de Administração Pública, Rio de Janeiro, v. 42, n. 6, p. 1041-1067, novembro/dezembro, 2008.

SARAIVA, E. V.; CARRIERI, A. de P. Citações e não citações na produção acadêmica de estratégia no Brasil: uma reflexão crítica. Revista de Administração da USP, São Paulo, v. 44, n. 2, p. 158-166, abril/junho, 2009.

ULLAH, M.; BUTT, I. F.; HAROON, M. The journal of ayub medical college: a 10-year bibliometric study. Health Information and Libraries Journal, EUA, v. 25, n. 2, p. 116-124, junho, 2008.

WASSERMAN, S.; FAUST, K. Social network analysis: methods and applications. Cambridge: Cambridge University Press, 1994.

Artigo recebido em: 13/07/2013

Aprovado em: 10/04/2014 